\title{
INFLUENCE OF SERVICE QUALITY AND FARE TOWARD CUSTOMER SATISFACTION AND ITS IMPACT ON CUSTOMER LOYALTY OF EXPRESS TAXI IN JAKARTA
}

\author{
Dr. Mohamad Rizan, S.E., M.M. \\ Fakultas Ekonomi Universitas Negeri Jakarta \\ email:mohamadrizan72@gmail.com \\ Erwin Fadillah \\ Fakultas Ekonomi Universitas Negeri Jakarta \\ email: erwinfad@gmail.com \\ Agung Kresnamurti Rivai P, S.T., M.M. \\ Fakultas Ekonomi Universitas Negeri Jakarta \\ email:ak_prabu99@yahoo.com
}

\begin{abstract}
The purpose of this study was to: to examine empirically the effect of service quality to customer satisfaction on Express taxi, to examine empirically the effect of fare to customer satisfaction on Express taxi, to examine empirically the effect of customer satisfaction to customer loyalty on Express taxi, to examine empirically the effect of service quality to customer loyalty on Express taxi, and to examine empirically the effect of fare to customer loyalty on Express taxi. Data collection using survey methods. Sample of this study are 200 respondents who have using services of Express taxi more than two times in last three months. Data analysis using SPSS version 23 and SEM (Structural Equation Modeling) LISREL version 8.7. Results of hypothesis testing showed: service quality have positive and significant effect on customer satisfaction, fare have positive and significant effect on customer satisfaction, customer satisfaction have positive and significant effect on customer loyalty, service quality have positive and not significant effect to on customer loyalty. fare have positive and significant effect to on customer loyalty. Rated fit model with value of RMSEA 0.043, value of RMR 0.043, value of CMIN/DF 1.88, value of NFI 0.96, value of NNFI 0.98, and value of CFI 0.98. The results of this research beneficial to transportation company, especially Express taxi in Jakarta, to create better strategy in improving customer loyalty.
\end{abstract}

Keywords: service quality, fare, customer satisfaction, customer loyalty, transportation 


\section{PENDAHULUAN}

\section{Latar Belakang Masalah}

Transportasi adalah proses pemindahan manusia, hewan ataupun barang dari tempat asal ke tempat tujuannya dengan memakai suatu alat yang dapat digerakan oleh makhluk hidup atau mesin. Transportasi berfungsi sebagai sarana pemenuh kebutuhan manusia untuk memindahkan penumpang atau barang ke tempat lain yang dituju. Transportasi sangat erat kaitannya dengan kehidupan manusia, khususnya di era globalisasi yang mana manusia cenderung melakukan perpindahan atau pengiriman barang dari satu tempat ke tempat yang lain.

Transportasi secara umum juga dapat menjadi pendorong kemakmuran dengan adanya transaksi yang terjadi saat menyediakan jasa angkutan. Dilihat dari jalur yang digunakan, transportasi dibagi menjadi tiga, yaitu transportasi darat, transportasi laut, dan transportasi udara.

Transportasi darat merupakan moda transportasi yang paling dominan di Indonesia dibandingkan tranportasi lainnya seperti transportasi udara dan transportasi laut. Hal ini ditunjukkan dari data OD Nasional 2001 yang menggambarkan bahwa $\pm 95 \%$ perjalanan penumpang dan barang menggunakan moda transportasi darat. Besarnya persentase tersebut merefleksikan tingginya ketergantungan penduduk Indonesia terhadap moda transportasi ini. Karena itulah transportasi darat sangat diperlukan oleh suatu daerah atau negara guna memperlancar mobilisasi dan komunikasi serta teknologi informasi.

Jakarta sebagai kota yang sibuk dan padat penduduk sangat membutuhkan transportasi yang dapat diandalkan untuk berkegiatan sehari-hari. Akibat padatnya penduduk Jakarta, kemacetan pun tidak dapat dihindari. Banyaknya kemacetan di berbagai lokasi di jalanan Jakarta membuat sebagian pengguna kendaraan pribadi malas membawa mobil/motor mereka. Pertimbangan melewati macet di saat berangkat dan pulang kerja tentunya akan melelahkan jika membawa kendaraan sendiri, belum lagi stress yang dapat ditimbulkan setelahnya.

Sayangnya, fasilitas transportasi umum yang ditawarkan pemerintah yang ada saat ini masih belum cukup baik. Transportasi umum yang ada saat ini masih dinilai kurang memuaskan khususnya soal keamanan, pelayanan dan kenyamanan saat menggunakannya.

Transportasi umum yang ada sekarang ini seperti bis, kereta, angkot, dan taksi merupakan pilihan yang tersedia jika memilih tidak menggunakan kendaraan pribadi. Di antara pilihan itu semua, tentu setiap orang memiliki pilihannya masing-masing sesuai 
dengan kebutuhan, dan untuk angkutan yang menawarkan kenyamanan paling tinggi adalah angkutan taksi.

Taksi adalah pilihan yang lebih nyaman karena tidak perlu berdesakkan dengan orang lain, bebas panas ataupun hujan, serta tidak perlu berganti angkutan lain untuk sampai ke tempat tujuan yang tidak bisa dijangkau kendaraan umum lainnya. Taksi juga menjadi pilihan karena tidak membuang waktu seperti kendaraan umum lainnya, taksi tidak "ngetem" untuk menunggu penumpang lain, juga tidak perlu ke lokasi khusus (seperti halte/stasiun) untuk didapatkan. Taksi merupakan pilihan yang eksklusif, karena itu pula dinilai lebih aman dari kendaraan umum lainnya. Kita dapat mencatat nomor kode taksi dan melihat identitas supirnya secara jelas di kartu pengenal yang tertera pada dashboard di kursi penumpang depan.

Banyaknya jumlah perusahaan taksi konvensional dan ribuan armada yang beroperasi di Jakarta secara langsung menciptakan persaingan yang cukup ketat, belum lagi ditambah dengan menghadapi persaingan dengan hadirnya taksi berbasis aplikasi seperti GrabCar, GrabTaxi, Go-Car, dan Uber X. Angka total taksi konvensional sendiri mengalami penurunan jumlah armada di Jakarta, yakni 27.239 kendaraan pada 2013 menjadi 27.079 kendaraan pada 2014, yang berarti mengalami penurunan sebesar $0.59 \%$ pada 2014 (BPS DKI Jakarta, Statistik Transportasi DKI Jakarta, 2015).

Pesatnya persaingan industri jasa angkutan di Indonesia bukan hanya disebabkan oleh globalisasi, tetapi lebih disebabkan karena pelanggan yang semakin cerdas, sadar harga, dan banyak menuntut. Kemajuan teknologi komunikasi juga ikut berperan meningkatkan intensitas persaingan, karena memberi pelanggan akses informasi yang lebih banyak tentang berbagai macam produk yang ditawarkan. Kondisi tersebut menyebabkan pelanggan memiliki pilihan yang lebih banyak dalam menggunakan uang yang dimilikinya.

Persaingan ketat ini membuat para pelaku bisnis industri taksi harus menemukan berbagai kemungkinan untuk mengalahkan para pesaingnya, di antaranya adalah dengan meningkatkan pelayanan dan menyesuaikan tarif dengan kondisi pasar. Ketua Organda DKI sudah menjelaskan arahan pemerintah untuk menggunakan tarif baru yang telah disesuaikan dengan kondisi pasar saat ini. Selain tarif bus kecil dan bus kota, Organda DKI Jakarta juga menurunkan tarif batas bawah taksi, dari Rp 7.500 jadi Rp 6.500. Sedangkan untuk hitungan rupiah per kilometer, turun dari Rp 4.000 jadi 3.500. "Waiting time taksi juga turun, dari Rp 48.000 jadi Rp 42.000. Dari 34 perusahaan taksi yang beraktivitas di Jakarta, taksi Express merupakan salah satu merek yang paling terkenal. 
Dari total 27.079 armada taksi di Jakarta, sebanyak 2500 armada milik PT Express Transindo Utama, yakni perusahaan dari taksi Express.

PT Express Transindo Utama tergabung dalam Express Group yang memberikan jasa pelayanan transportasi di Indonesia. Express Group berdiri pada April 1989 sebagai anak perusahaan Rajawali Corpora. Selain jasa taksi regular, Express Group juga menyediakan jasa taksi premium, limousine, serta bus untuk memenuhi berbagai keperluan pelanggan. Express Group saat ini telah melayani banyak wilayah seperti Jabodetabek, Medan, Padang, Surabaya, Semarang, Bandung, Bali, Lombok.

Keunggulan dalam memberikan tarif lebih murah dari kompetitor adalah strategi taksi Express dalam menjalankan bisnisnya. Hal tersebut yang selama ini dirasakan masyarakat sehingga banyak memilih taksi Express sebagai pilihan. Terbukti dengan konsistensi taksi Express menjadi “TOP BRAND” pada tahun 2014 dan 2015 Top Brand Award dalam kategori taksi.

Pada tahun 2014 dan 2015 taksi Express berada di posisi kedua dan berhasil meraih penghargaan Top Brand Indonesia dalam kategori taksi. Taksi Express berada di posisi dua dengan nilai TBI 10,1\% pada 2014 dan 10\% pada 2015. Meskipun jauh dengan pesaingnya taksi Blue Bird yang selalu mendapat TBI di atas 60\%, taksi Express tetap merupakan pesaing yang paling diperhitungkan dalam industri angkutan taksi.

Saat ini taksi Express sudah mengikuti peraturan baru yang ditentukan oleh organda, yaitu Rp 6.500 tarif buka pintu, Rp 3.500 per kilometer, dan Rp 42.000 tarif tunggu per jamnya. Penyesuaian kebijakan ini merupakan tanggapan pemerintah dari aksi mogok kerja dan demo para supir taksi di Jakarta 22 Maret 2016 lalu. Hal ini tidak menguntungkan pihak taksi Express karena kebijakan ini memaksa para kompetitor menyamai tarif mereka, sehingga tidak ada lagi perbedaan tarif pada taksi reguler. Ini juga menjadikan mereka harus berbenah diri untuk meningkatkan kualitasnya yang selama ini dipandang kurang baik mengingat tarif yang lebih murah.

Kotler dan Keller mengatakan bahwa banyak pelanggan menggunakan harga sebagai indikator dari kualitas. Citra dari harga yang ditimbulkan sangat efektif terhadap produk yang meningkatkan ego dari pelanggan seperti parfum dan mobil mewah (Kotler dan Keller, 2016: p.448).

Berikut adalah keterangan laba (rugi) bersih dari taksi express yang menunjukkan penurunan laba dalam beberapa tahun terakhir: 


\section{Tabel I}

Laba (Rugi) Bersih Taksi Express 2014 - 2016

\begin{tabular}{lcc}
\hline Tahun & Laba (Rugi) Bersih [Miliar] & Persentase \\
\hline 2013 & Rp 132,423 M & \\
\hline 2014 & $\operatorname{Rp~118,710~M~}$ & $-10,36 \%$ \\
\hline 2015 & $\operatorname{Rp~33,246~M}$ & $-72,83 \%$ \\
\hline Q1/2016 & $($ Rp 9,85 M) & $-151,5 \%(\mathrm{Q} 1 / 2015)$ \\
Sumber: Data diolah peneliti $(2016)$ &
\end{tabular}

Masalah juga terdapat pada penurunan pendapatan. Pada 31 Maret 2016 (Q1/2016) tercatat pendapatan usaha sebesar Rp210,48 M. Data ini menunjukkan penurunan pendapatan yang cukup besar yaitu Rp247,10 M pada tahun lalu (Q1/2015). Sejak 2013 hingga 2015 taksi Express terus terjadi penurunan laba bersih meskipun mengalami kenaikan pendapatan. Kenaikan pendapatan ini salah satunya karena inflasi secara umum dan harga kian bertambah mahal. Penurunan laba kerap terjadi karena daya beli masyarakat tidak meningkat beriringan dengan kenaikan harga produk. Berkurangnya pendapatan dan meruginya taksi Express pada kuartal 12016 ini mengindikasikan bahwa pelanggan taksi Express mulai menurun dan ini menunjukkan berkurangnya loyalitas pelanggan terhadap taksi Express.

Berikut Tabel 2 yang menunjukkan kenaikan pendapatan yang didapat dalam beberapa tahun terakhir, tetapi menurun dalam persentase tahunan.

Tabel 2

Jumlah Pendapatan Taksi Express 2013 - 2016

\begin{tabular}{ccc}
\hline \multirow{2}{*}{ Tahun } & Jumlah Pendapatan [Miliar] & Persentase \\
\hline 2013 & Rp 686,917 M & \\
\hline 2014 & Rp 889,723 M & $29,52 \%$ \\
\hline 2015 & Rp 970,093 M & $9,03 \%$ \\
\hline Q1/2016 & Rp 210,48 M & $-14,82 \%(\mathrm{Q} 1 / 2015)$
\end{tabular}

Sumber: Data diolah peneliti (2016) 
Menurunnya loyalitas konsumen taksi Express tersebut diduga disebabkan oleh buruknya kualitas pelayanan. Selain loyalitas pelanggan yang menurun akibat buruknya kualitas pelayanan, dampak lain yang ditimbulkan adalah menurunnya kepuasan pelanggan yang juga berakibat fatal terhadap hilangnya loyalitas pelanggan. Faktor tarif yang dirasa tinggi juga mengurangi niat menggunakan ulang jasa yang disediakan, yang berarti turunnya loyalitas serta kepuasan pelanggan.

Berdasarkan latar belakang masalah tersebut dan melihat berbagai uraian di atas, penulis melakukan penelitian yang berjudul: "Pengaruh Kualitas Pelayanan dan Tarif Terhadap Kepuasan Pelanggan Serta Dampaknya Pada Loyalitas Pelanggan Taksi Express di Jakarta."

\section{Tujuan Penelitian}

Tujuan penelitian yang ingin dicapai dalam penelitian ini adalah:

1. Untuk mengetahui deskripsi dari Kualitas Pelayanan (Service Quality), Tarif (Fare), Kepuasan Pelanggan (Customer Satisfaction) dan Loyalitas Pelanggan (Customer Loyalty) pada Taksi Express.

2. Untuk menguji pengaruh Kualitas Pelayanan (Service Quality) terhadap Kepuasan Pelanggan (Customer Satisfaction) pada Taksi Express.

3. Untuk menguji pengaruh Tarif (Fare) terhadap Kepuasan Pelanggan (Customer Satisfaction) pada Taksi Express.

4. Untuk menguji pengaruh Kepuasan Pelanggan (Customer Satisfaction) terhadap Loyalitas Pelanggan (Customer Loyalty) pada Taksi Express.

5. Untuk menguji pengaruh Kualitas Pelayanan (Service Quality) terhadap Loyalitas Pelanggan (Customer Loyalty) pada Taksi Express.

6. Untuk menguji pengaruh Tarif (Fare) terhadap Loyalitas Pelanggan (Customer Loyalty) pada Taksi Express. 


\section{KAJIAN TEORI}

\section{Kualitas Pelayanan}

Menurut Gronroos dalam Services Marketing (2011) kualitas pelayanan adalah hasil dari suatu proses evaluasi dimana pelanggan membandingkan persepsi mereka terhadap pelayanan dan hasilnya, dengan apa yang mereka harapkan.

Kotler dan Keller (2012) menyatakan kualitas pelayanan adalah totalitas fitur dan karakteristik dari suatu produk atau jasa yang menanggung pada kemampuannya untuk memuaskan kebutuhan yang dinyatakan atau tersirat .

Menurut Boone dan Kurtz (2015) kualitas pelayanan mengacu pada kualitas yang diharapkan dan dirasakan oleh konsumen dari pelayanan yang ditawarkan, yang memiliki pengaruh besar pada daya saing perusahaan. Hal ini adalah penentu utama dari kepuasan atau ketidakpuasan pelanggan.

Menurut James A. Fitzsimmons dan Mona J Fitzsimmon (2006) menjelaskan bahwa kualitas pelayanan adalah sesuatu yang kompleks, dan pelanggan akan menilai kualitas pelayanan melalui lima prinsip dimensi pelayanan sebagai ukurannya, yaitu sebagai berikut :

1. Reliabilitas (Reliability)

2. Responsif (Responsiveness)

3. Kepastian/jaminan (Assurance)

4. Empati (Empathy)

5. Nyata (Tangibles)

\section{Tarif}

Teori tarif mengambil terminologi dari teori harga, karena dalam pengertiannya tarif adalah biaya yang dibebankan atas jasa. Harga adalah sejumlah uang yang ditagihkan atas suatu produk atau jasa, atau jumlah dari nilai yang ditukarkan para pelanggan untuk memperoleh manfaat dari memiliki atau menggunakan produk atau jasa (Kotler dan Armstrong 2014: p310).

Menurut ahli, harga adalah apa yang pelanggan bayarkan atau berikan yang diberlakukan untuk produk atau jasa (Kim et al. 2012: p.5042).

Dimensi yang dapat mengukur harga menurut Assauri terbagi menjadi tiga, yaitu:

1. Tingkat harga; di mana pelanggan merasa wajar jika produk atau jasa dari perusahaan yang berbeda menetapkan pada harga yang berbeda pula. 
2. Potongan harga; hasil dari pengurangan harga dasar atau harga tercatat atau harga terdaftar.

3. Cara pembayaran; syarat pembayaran dalam kaitannya dengan alat pembayaran seperti tunai, kredit, transfer dsb.

\section{Kepuasan Pelanggan}

Menurut Kotler dan Keller kepuasan adalah perasaan seseorang kesenangan atau kekecewaan yang dihasilkan dari membandingkan kinerja produk yang dirasakan dengan harapan. Jika kinerja jatuh jauh dari harapan, maka pelanggan tidak puas. Jika cocok harapan, pelanggan puas. Jika melebihi harapan, pelanggan sangat puas atau senang (Irawan, 2012: p.150).

Kepuasan adalah suatu sikap yang diputuskan berdasarkan pengalaman yang didapatkan. Sangat dibutuhkan penelitian untuk membuktikan ada atau tidaknya harapan sebelumnya yang merupakan bagian terpenting dalam kepuasan (Lovelock dan Wirtz 2011: p.76)

Menurut Lupiyoadi dan Hamdani, kepuasan pelanggan dapat diidentifikasi dalam beberapa faktor dimensi, yaitu:

1. Product-related factors, yaitu faktor-faktor yang digunakan untuk pengembangan suatu produk yang melibatkan penantian manfaat yang akan diberikan. Value-ToPrice Relationship, Product Quality, Product Benefits, Produc Features, Product Design, Produc Reliability and Consistency, Range of Product or Service.

2. Service-related factors, yaitu faktor-faktor yang berkaitan dengan pelayanan suatu perusahaan, yaitu: Guarantee or Warranty, Complaint Handling, Resolution of problem, Delivery.

3. Purchase factors, yaitu faktor-factor yang berkaitan dengan pembelian, meliputi: Ease or convenience of Acquisition, Courtesy.

\section{Loyalitas Pelanggan}

Lovelock, Wirtz, dan Mussry (2011) mendefinisikan customer loyalty sebagai perilaku yang mencakup preferensi, kesukaan, dan itikad di masa mendatang untuk menggambarkan kesediaan pelanggan agar senantiasa menggunakan produk perusahaan dalam jangka panjang. 
Menurut Swastha dalam Nurlaili \& Andi Wijayanto (2013) definisi customer loyalty adalah kesetiaan konsumen untuk terus menggunakan produk yang sama dari suatu perusahaan.

Menurut Kotler dan Keller (2012) customer loyalty adalah komitmen yang dipegang teguh untuk membeli kembali produk atau jasa yang disukai di masa depan.

Menurut Uncles et. al dalam Nasir et.al (2014), customer loyalty dapat dikelompokkan menjadi tiga dimensi yaitu

1. Attitudinal-loyalty.

2. Behavioral-loyalty.

3. Cognitive Loyalty.

\section{Kerangka Teoretik}

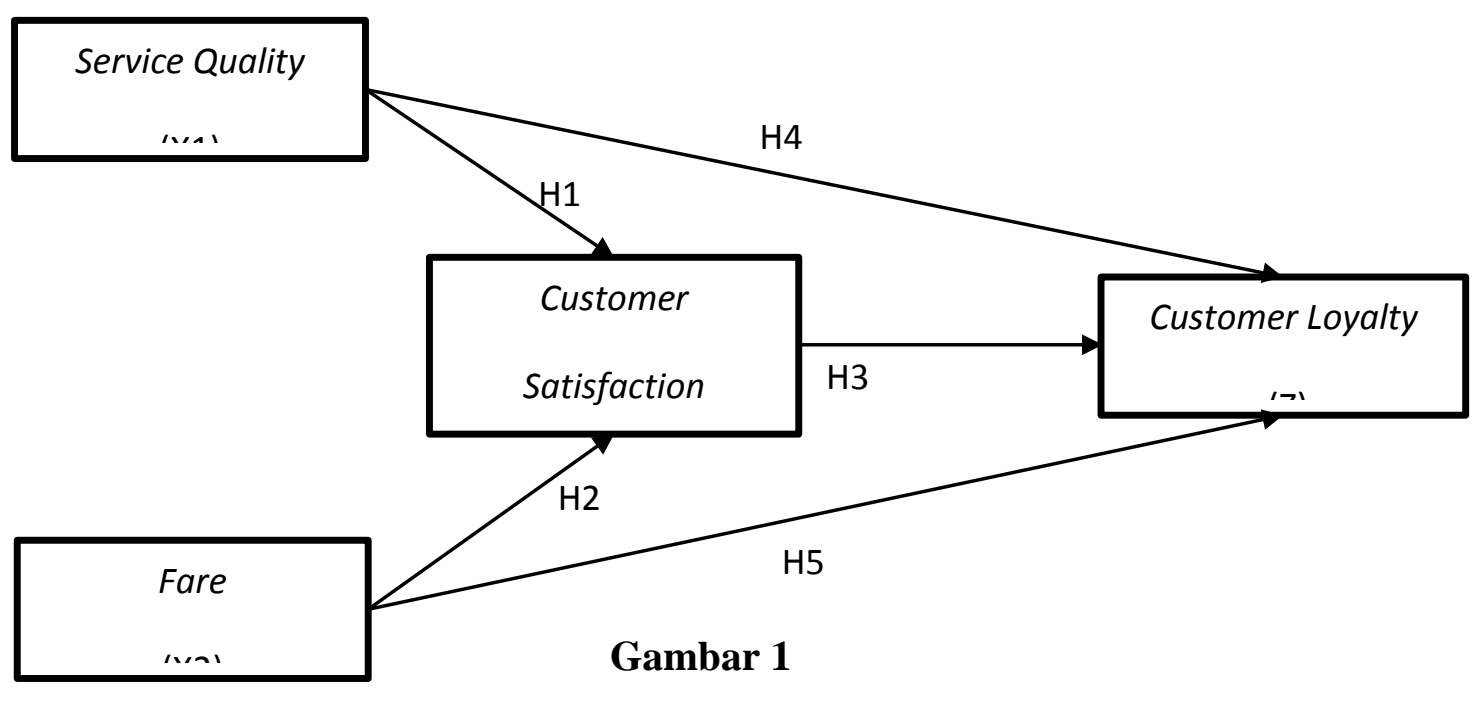

Model Penelitian

\section{Hipotesis}

$\mathrm{H}_{1}$ : Terdapat pengaruh positif dan signifikan dari Kualitas Pelayanan terhadap Kepuasan Pelanggan taksi Express.

$\mathrm{H}_{2}$ : Terdapat pengaruh positif dan signifikan dari Tarif terhadap Kepuasan Pelanggan taksi Express.

$\mathrm{H}_{3}$ : Terdapat pengaruh positif dan signifikan dari Kepuasan Pelanggan terhadap Loyalitas pelanggan taksi Express.

$\mathrm{H}_{4}$ : Terdapat pengaruh positif dan signifikan dari terhadap Kualitas Pelayanan terhadap Loyalitas Pelanggan taksi Express. 
$\mathrm{H}_{5}$ : Terdapat pengaruh positif dan signifikan dari Tarif terhadap Loyalitas Pelanggan taksi Express

\section{METODE PENELITIAN}

Metode yang digunakan dalam penelitian ini adalah penelitian kuantitatif, dimana penelitian kuantitatif menurut Sugiyono (2012) adalah penelitian yang bersifat deskriptif dan cenderung menggunakan analisis pendekatan induktif. Penelitian kuantitatif adalah penelitian yang menitik beratkan pada pengukuran dan analisis hubungan sebab akibat setiap variabel.

Penelitian yang akan digunakan adalah deskriptif dan kausal. Menurut Malhotra (2009), riset deskriptif adalah suatu jenis riset konklusif yang mempunyai tujuan utama menguraikan suatu karakteristik. Sedangkan riset kausal bertujuan untuk mendapatkan bukti hubungan sebab-akibat antara variabel independen terhadap variabel dependen.

\section{Metode Penentuan Populasi dan Sampel}

Menurut Sekaran dan Bougie (2013), populasi mengacu pada keseluruhan kelompok orang, kejadian, atau hal minat yang ingin peneliti investigasi. Populasi dalam penelitian ini adalah pelanggan yang telah lebih dari dua kali dalam tiga bulan terakhir menggunakan jasa taksi Express di Jakarta.

Jenis populasi yang akan diteliti adalah populasi infinite yaitu objek dengan ukuran yang tidak terhingga, yang mana peneliti dalam penelitian ini tidak mengetahui jumlah pasti pelanggan yang telah lebih dari dua kali dalam tiga bulan terakhir menggunakan jasa taksi Express di Jakarta.

Penentuan jumlah sampel ditentukan dengan persyaratan yang ditentukan oleh Hair et. al (2013). Hair et al menyatakan bahwa jumlah sampel yang diambil minimal 5 kali dari jumlah parameter yang dipergunakan dalam penelitian. Lebih lanjut Hair et.al menyebutkan bahwa critical sample size untuk analisis menggunakan LISREL adalah 200 sampel.

Metode sampling yang digunakan dalam penelitian ini adalah purposive sampling. Menurut Sekaran (2007), purposive sampling adalah peneliti memperoleh informasi dari mereka yang paling siap dan memenuhi beberapa kriteria yang dibutuhkan dalam memberikan informasi. Alasan penggunaan 
purposive sampling adalah diharapkan sampel yang akan diambil benar-benar memenuhi kriteria yang sesuai dengan penelitian yang akan dilakukan.

Sampel dalam penelitian ini sebanyak 200 sampel. Dalam hal ini responden yang memenuhi kriteria adalah pelanggan yang telah lebih dari dua kali dalam tiga bulan terakhir menggunakan jasa taksi Express di Jakarta. Responden dalam penelitian ini akan diambil di pusat perbelanjaan Plaza Blok M.

\section{Metode Analisis Data}

Tujuan metode analisis data adalah untuk menginterprestasikan dan menarik kesimpulan dari sejumlah data yang terkumpul. Peneliti menggunakan perangkat lunak SPSS versi 23 dan SEM (Structural Equation Model) dari paket statistik LISREL 8.7 untuk mengolah dan menganalisis data hasil penelitian.

\section{HASIL DAN PEMBAHASAN}

\section{Analisis Faktor Variabel Kualitas Pelayanan}

Hasil KMO variabel Kualitas Pelayanan menunjukan KMO >0,5 yaitu sebesar 0,925. Barlett's Test of Sphericity mempunyai signifikansi 0,00 telah memenuhi kriteria $<0,05$. Hal ini menyatakan bahwa data yang telah diambil dapat di faktorkan.

Hasil uji reliabilitas menunjukkan bahwa variabel kualitas pelayanan memiliki 16 pernyataan yang semuanya bersifat reliabel. Hal tersebut dapat dilihat dari hasil koefisien cronbach's alpha tiap pernyataan lebih besar dari 0.6.

\section{Analisis Faktor Variabel Tarif}

Hasil KMO variabel Tarif berdasarkan tabel IV.9 menunjukan KMO >0,5 yaitu sebesar 0,727. Barlett's Test of Sphericity mempunyai signifikansi 0,00 telah memenuhi kriteria $<0,05$. Hal ini menyatakan bahwa data yang telah diambil dapat di faktorkan.

Hasil uji reliabilitas menunjukkan bahwa variabel tarif memiliki 9 pernyataan yang semuanya bersifat reliabel. Hal tersebut dapat dilihat dari hasil koefisien cronbach's alpha tiap pernyataan lebih besar dari 0.6.

\section{Analisis Faktor Variabel Kepuasan Pelanggan}

Hasil KMO variabel Kepuasan pelanggan berdasarkan tabel IV.10 menunjukan KMO >0,5 yaitu sebesar 0,930. Barlett's Test of Sphericity mempunyai signifikansi 0,00 
telah memenuhi kriteria $<0,05$. Hal ini menyatakan bahwa data yang telah diambil dapat di faktorkan.

Hasil uji reliabilitas diatas menunjukkan bahwa kepuasan pelanggan memiliki 13 pernyataan yang semuanya bersifat reliabel. Hal tersebut dapat dilihat dari hasil koefisien cronbach's alpha tiap pernyataan lebih besar dari 0.6.

\section{Analisis Faktor Variabel Loyalitas Pelanggan}

Hasil KMO variabel Loyalitas Pelanggan berdasarkan tabel IV.11 menunjukan KMO >0,5 yaitu sebesar 0,898. Barlett's Test of Sphericity mempunyai signifikansi 0,00 telah memenuhi kriteria $<0,05$. Hal ini menyatakan bahwa data yang telah diambil dapat di faktorkan.

Hasil uji reliabilitas menunjukkan bahwa variabel loyalitas pelanggan memiliki 8 pernyataan yang semuanya bersifat reliabel. Hal tersebut dapat dilihat dari hasil koefisien cronbach's alpha tiap pernyataan lebih besar dari 0.6.

\section{Hasil Uji Hipotesis}

Tabel 3

Model Persamaan Struktural

\begin{tabular}{|c|c|c|c|c|c|c|}
\hline & $\begin{array}{c}\text { Variabel } \\
\text { Bebas }\end{array}$ & & $\begin{array}{l}\text { Variabel } \\
\text { Terikat }\end{array}$ & $\begin{array}{c}\text { t- } \\
\text { values }\end{array}$ & 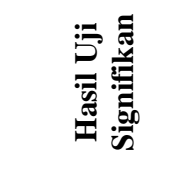 & 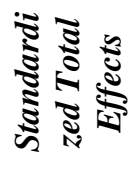 \\
\hline H1 & $\begin{array}{l}\text { Kualitas } \\
\text { Pelayanan }\end{array}$ & $\rightarrow$ & $\begin{array}{l}\text { Kepuasan } \\
\text { Pelanggan }\end{array}$ & 7.28 & Signifikan & 0.58 \\
\hline $\mathrm{H} 2$ & Tarif & $\rightarrow$ & $\begin{array}{l}\text { Kepuasan } \\
\text { pelanggan }\end{array}$ & 5.94 & Signifikan & 0.41 \\
\hline $\mathrm{H} 3$ & $\begin{array}{l}\text { Kepuasan } \\
\text { pelanggan }\end{array}$ & $\rightarrow$ & $\begin{array}{l}\text { Loyalitas } \\
\text { pelanggan }\end{array}$ & 3.34 & Signifikan & 0.51 \\
\hline $\mathrm{H} 4$ & $\begin{array}{l}\text { Kualitas } \\
\text { Pelayanan }\end{array}$ & $\rightarrow$ & $\begin{array}{l}\text { Loyalitas } \\
\text { Pelanggan }\end{array}$ & 0.31 & $\begin{array}{c}\text { Tidak } \\
\text { Signifikan }\end{array}$ & 0.33 \\
\hline H5 & Tarif & $\rightarrow$ & $\begin{array}{l}\text { Loyalitas } \\
\text { Pelanggan }\end{array}$ & 3.05 & Signifikan & 0.50 \\
\hline
\end{tabular}


Apabila $t$-value pada hasil persamaan struktural lebih besar dari 1.96 maka terdapat pengaruh yang signifikan antar variabel, jika nilai $t$-value lebih kecil dari 1.96 maka pengaruh antar variabel tidak signifikan.

Pengujian hipotesis dilakukan dengan melihat nilai standardized total effects pada model persamaan struktural. Berdasarkan tabel IV. 24 maka dapat dilihat hasil dari uji hipotesis sebagai berikut:

H1: Variabel kualitas pelayanan terhadap kepuasan pelanggan pada model ini memiliki nilai standardized total effects sebesar 0.58 , sehingga hipotesis 1 yang menyatakan kualitas pelayanan terhadap kepuasan pelanggan berpengaruh positif sebesar 58\% dapat diterima.

H2: Variabel tarif terhadap kepuasan pelanggan pada model ini memiliki nilai standardized total effects sebesar 0.41 , sehingga hipotesis 2 yang menyatakan tarif terhadap kepuasan pelanggan berpengaruh positif sebesar $41 \%$ dan dapat diterima.

H3: Variabel kepuasan pelanggan terhadap loyalitas pelanggan pada model ini memiliki nilai standardized total effects sebesar 0.51, sehingga hipotesis 3 yang menyatakan kepuasan pelanggan terhadap loyalitas pelanggan berpengaruh positif sebesar $51 \%$ dan dapat diterima.

H4: Variabel kualitas pelayanan terhadap loyalitas pelanggan pada model ini memiliki nilai standardized total effects sebesar 0.33 , sehingga hipotesis 4 yang menyatakan kualitas pelayanan terhadap loyalitas pelanggan berpengaruh positif sebesar 33\% ditolak

\section{karena tidak signifikan.}

H5: Variabel tarif terhadap loyalitas pelanggan pada model ini memiliki nilai standardized total effects sebesar 0.50 , sehingga hipotesis 5 yang menyatakan tarif terhadap loyalitas pelanggan berpengaruh positif sebesar 50\% dan dapat diterima. 


\section{Uji Pengaruh Langsung dan Tidak Langsung}

Tabel 4

Pengaruh Langsung dan Tidak Langsung

\begin{tabular}{llccc}
\hline $\begin{array}{l}\text { Variabel } \\
\text { Bebas }\end{array}$ & & $\begin{array}{l}\text { Variabel } \\
\text { Terikat }\end{array}$ & $\begin{array}{l}\text { Pengaruh } \\
\text { Langsung }\end{array}$ & $\begin{array}{l}\text { Pengaruh Tidak } \\
\text { Langsung }\end{array}$ \\
\hline $\begin{array}{l}\text { Kualitas } \\
\text { Pelayanan }\end{array}$ & $\rightarrow$ & $\begin{array}{l}\text { Kepuasan } \\
\text { Pelanggan }\end{array}$ & 0.58 & - \\
Tarif & $\rightarrow$ & $\begin{array}{l}\text { Kepuasan } \\
\text { Pelanggan }\end{array}$ & 0.41 & - \\
$\begin{array}{l}\text { Kepuasan } \\
\text { Pelanggan }\end{array}$ & $\rightarrow$ & $\begin{array}{l}\text { Loyalitas } \\
\text { Pelanggan }\end{array}$ & 0.51 & - \\
$\begin{array}{l}\text { Kualitas } \\
\text { Pelayanan } \\
\text { Tarif }\end{array}$ & $\rightarrow$ & $\begin{array}{l}\text { Loyalitas } \\
\text { Pelanggan } \\
\text { Loyalitas } \\
\text { Pelanggan }\end{array}$ & 0.33 & 0.29 \\
\hline
\end{tabular}

Uji pengaruh langsung dan tidak langsung dilakukan untuk mengetahui adakah pengaruh langsung maupun tidak langsung variabel bebas yang mempengaruhi variabel terikat yang dinyatakan dalam nilai standardized total effects. Berdasarkan hasil pada tabel di atas dapat dilihat pengaruh langsung variabel kualitas pelayanan terhadap kepuasan pelanggan sebesar 0.58 , pengaruh langsung variabel tarif terhadap kepuasan pelanggan sebesar 0.41 , pengaruh variabel kepuasan pelanggan terhadap loyalitas pelanggan sebesar 0.51 , pengaruh variabel kualitas pelayanan terhadap loyalitas pelanggan sebesar 0.33 , pengaruh variabel tarif terhadap loyalitas pelanggan sebesar 0.50 .

Pengaruh tidak langsung hanya dimiliki oleh variabel kualitas pelayanan dan tarif terhadap loyalitas pelanggan. Hal ini dikarenakan ada variabel mediasi pada model penelitian antara kualitas pelayanan dan tarif, yaitu variabel kepuasan pelanggan. Pengaruh tidak langsung variabel kualitas pelayanan terhadap loyalitas pelanggan sebesar 0.29 dan pengaruh tidak langsung variabel tarif terhadap loyalitas pelanggan sebesar 0.21.

\section{KESIMPULAN DAN SARAN}

\section{Kesimpulan}

Tujuan penelitian ini adalah untuk mengetahui pengaruh kualitas pelayanan terhadap kepuasan pelanggan, pengaruh tarif terhadap kepuasan pelangganan, pengaruh kepuasan pelangganan terhadap loyalitas pelanggan, pengaruh kualitas pelayanan terhadap loyalitas pelanggan, pengaruh tarif terhadap loyalitas pelanggan. Jumlah responden yang diambil sebanyak 200 responden. Responden yang terlibat dalam penelitian ini adalah pelanggan 
yang menggunakan jasa transportasi taksi Express lebih dari dua kali dalam tiga bulan terakhir di Plaza Blok M. Pengumpulan data dilakukan dengan cara penyebaran kuesioner.

Metode analisis untuk pengolahan data penelitian menggunakan SPSS untuk pengujian instrumen dan LISREL untuk confirmatory factor analysis. Setelah mengolah data primer mengenai variabel-variabel penelitian dapat disimpulkan sebagai berikut:

1. Hipotesis pertama menyatakan bahwa Kualitas Pelayanan berpengaruh positif dan signifikan terhadap Kepuasan Pelanggan taksi Express diterima. Ini berarti jika kualitas pelayanan taksi Express meningkat, maka kepuasan pelanggan taksi Express juga akan ikut naik secara signifikan.

2. Hipotesis kedua menyatakan bahwa Tarif berpengaruh positif dan signifikan terhadap Kepuasan Pelanggan taksi Express diterima. Ini berarti jika tarif taksi Express sesuai dengan harapan pelanggan, maka kepuasan pelanggan taksi Express akan meningkat secara signifikan.

3. Hipotesis ketiga menyatakan bahwa Kepuasan Pelanggan berpengaruh positif dan signifikan terhadap Loyalitas Pelanggan taksi Express diterima. Ini berarti jika kepuasan pelanggan taksi Express meningkat, maka loyalitas pelanggan taksi Express akan ikut meningkat secara signifikan.

4. Hipotesis keempat menyatakan bahwa Kualitas Pelayanan berpengaruh positif dan signifikan terhadap Loyalitas Pelanggan taksi Express ditolak. Ini berarti jika hanya kualitas pelayanan taksi Express meningkat tanpa meningkatkan kepuasan pelanggan taksi Express, maka loyalitas pelanggan taksi Express akan ikut meningkat tetapi tidak signifikan. Hal ini terjadi karena kualitas pelayanan pada industri taksi hampir sama dan tidak bisa menjadi andalan taksi Express dalam bersaing. Taksi Express juga memiliki citra yang melekat sejak lama, yaitu soal tarifnya yang murah, bukan kualitas pelayanannya yang menjadi keunggulan.

5. Hipotesis kelima menyatakan bahwa Tarif berpengaruh positif dan signifikan terhadap Loyalitas Pelanggan taksi Express diterima. Ini berarti jika tarif taksi Express sesuai dengan harapan pelanggan, maka loyalias pelanggan taksi Express akan ikut meningkat secara signifikan. 
Jurnal Riset Manajemen Sains Indonesia (JRMSI) | Vol 6, No. 2, 2015

\section{Saran}

Berdasarkan hasil uji penelitian dan kesimpulan, maka dapat diberikan beberapa saran, baik untuk penelitian selanjutnya dan untuk taksi Express. Saran-saran tersebut sebagai berikut :

\section{Saran untuk penelitian selanjutnya}

a. Penelitian ini dapat dilakukan kembali dengan objek penelitian yang berbeda, misalnya tentang bisnis penyedia layanan telekomunikasi.

b. Penelitian ini dapat dilakukan kembali dengan menggunakan variabel yang berbeda seperti: kepercayaan pelanggan, citra merek, dan minat menggunakan kembali agar dapat mengeksplorasi kemungkinan variabel lain yang dapat mempengaruhi loyalitas pelanggan.

c. Penelitian ini dapat dilakukan kembali dengan melakukan uji beda terhadap perusahaan pesaing yang beroperasi dengan cara yang sama yaitu bisnis transportasi umum seperti taksi Bluebird.

d. Penelitian ini dapat dilakukan kembali dengan penelitian pada kelas transportasi yang berbeda seperti taksi premium Tiara Express atau Silverbird .

e. Penelitian ini dapat dilanjutkan kembali dengan lingkup yang lebih luas yang akan memungkinkan mendapat tanggapan yang berbeda.

\section{Saran untuk taksi Express}

a. Taksi Express diharapkan lebih memperhatikan faktor kualitas pelayanan agar lebih baik lagi. Misalnya dengan memperbarui armada yang sudah tua, memberi pelatihan soft skill pada setiap pegawai, dan perekrutan supir yang ketat agar kepuasan pelanggan dan loyalitas pelanggan dapat bertahan bahkan meningkat. 
b. Taksi Express harus mampu bersaing dengan perusahaan taksi yang lain agar tidak tertinggal. Misalnya dengan mencontoh taksi Blue Bird sebagai kompetitor utama dengan mengedepankan kualitas yang baik. Persepsi masyarakat juga penting untuk keberlangsungan perusahaan, karena itu citra harus dijaga dan ditingkatkan.

c. Taksi Express dituntut untuk bersikap profesional. Misalnya dengan mau mendengar masukan pelanggan, menerapkan sistem baru agar armada mudah didapat, tidak menolak penumpang, jujur dan ikhlas dalam melayani pelanggan.

d. Taksi Express harus lebih mementingkan keinginan pelanggannya. Misalnya menanggapi keluhan pelanggan dengan sabar, karena taksi Express menjual jasanya apabila pelanggan tidak puas maka akan merugikan taksi Express sendiri.

e. Taksi Express harus melakukan sosialisasi akan terobosan mereka, yaitu aplikasi "myTrip". Dalam menghadapi persaingan, haruslah dengan pemikiran terbuka yang modern, misalnya saat ada transportasi pesaing baru berbasis aplikasi yang mengganggu pangsa pasar, hadapi juga dengan teknologi. Taksi Express sudah menjawab tantangan ini, tetapi pelaksanaannya saja yang belum tersebar merata.

f. Taksi Express dituntut untuk mempertahankan para pelanggan loyal. Taksi Express harus memperbaiki performanya agar pelanggan tidak beralih ke kompetitor dengan cara memberikan promo atau diskon kepada pelanggan yang loyal. Ini bisa dilakukan dengan mengadakan kerjasama dengan bank tertentu dan mendapatkan poin reward untuk setiap menggunakan jasa taksi Express. 
Jurnal Riset Manajemen Sains Indonesia (JRMSI) | Vol 6, No. 2, 2015

g. Taksi Express masih kurang dalam mempertahankan loyalitas pelanggan. Pelanggan yang menggunakan jasa taksi Express tidak sepenuhnya loyal pada produk tersebut. Hal ini dapat ditingkatkan dengan mengadakan loyalty program seperti acara fun-walk yang bisa didatangi bersama keluarga dan menjadikan merek taksi Express lebih dekat dengan publik.

Pelanggan taksi Express tidak terlalu bangga dengan menaiki armada tersebut. Karena rasa bangga terkait dengan citra suatu brand, taksi Express dapat melakukan branding yang baru dan lebih melekat di benak pelanggan. Hal ini bisa dilakukan dengan menjadi sponsor pada acara musik atau event internasional yang diprediksi akan ramai didatangi.

\section{DAFTAR PUSTAKA}

Aditia dan Suhaji, "Faktor-Faktor yang Mempengaruhi Kepuasan Pelanggan pada UD Pandan Wangi Semarang”, Sekolah Tinggi Ilmu Ekonomi Widya Manggala, 2012. p. 2

Antari Setiawati, "Studi Kepuasan Pelanggan Untuk Mencapai Loyalitas Pelanggan (Studi Kasus Pada Konsumen Toko Bangunan Bangun Rejeki Semarang)", Program Magister Universitas Diponegoro Semarang, 2009, p. 16

Ashis Bhave, "Customer Satisfaction Measurement", Symphony Technologies, http://goo.gl/lxw6RS (diakses tanggal 7 Maret 2016)

Bisnis.com, "Taksi Online Menjamur, Express Group Tak Tambah Armada", http://market.bisnis.com/read/20160602/192/553845/taksi-onlinemenjamur-express-group-tak-tambah-armada (Diakses 13 Juni 2016)

Boone \& Kurtz, Contemporary Management (United States : Cengage Learning) 2015.

BPS Provinsi DKI Jakarta, “Statistik Trasportasi DKI Jakarta 2015”, 2015.

Dedy Londong, "Kepuasan Pelanggan (Customer Satisfaction)", http://goo.gl/YK7Obu (diakses tanggal 14 Juni 2016)

Desy Purwanti Atmaja dan Martinus Febrian Adiwinata, "Pengaruh Produk, Harga, Lokasi Dan Kualitas Layanan Terhadap Keputusan Pembelian di Kopitiam Oey Surabaya”, p.553

Dinas Perhubungan, "Data Taksi Reguler dan Taksi Eksekutif DKI Jakarta”, Dinas Perhubungan dan Transportasi, 2015

Direktorat Jendral Perhubungan Darat, "Masterplan Transportasi Darat”, 2005 
Dwi Priyatno, Teknik Mudah dan Cepat Melakukan Analisis Data Penelitian dengan SPSS (Yogyakarta: Gava Media, 2010)

Haghighi et al., "Evaluation of factors affecting customer loyalty in the restaurant industry", African Journal of Business Management, Vol. 6(14), 2012, p.5042

Heesup Han, Sunghyup Sean Hyun, et. all, In-Flight Service Performance and Passenger Loyalty: A Cross-National (China/Korea) Study of Travelers Using Low-Cost Carriers, Journal of Travel \& Tourism Marketing, Vol. 31, 2014, p. 593

Husein Umar, "Faktor-faktor yang Memengaruhi Loyalitas Pelanggan pada Penerbangan Low Cost Carrier", Jurnal Manajemen Transportasi \& Logistik (JMTransLog) - Vol. 01 No. 02, Juli 2014, p. 128-129

IDX, "Laporan Keuangan Konsolidasian PT Express Transindo Utama Tbk" QI/2016, p.3

Irawan, "Dimensi Kualitas Layanan : Konsep dan Perkembangannya", Jurnal ISEI Jember, Vol. 2, No. 1, 2012, p. 2

Jackson R.S. Weenas, "Kualitas Produk, Harga, Promosi dan Kualitas Pelayanan Pengaruhnya Terhadap Keputusan Pembelian Spring Bed Comforta” Jurnal EMBA, Vol.1 No.4 Desember 2013, p.609

Jefri Sitorus, "Pengaruh Kualitas Pelayanan Dan Persepsi Harga Terhadap Loyalitas Konsumen Penerbangan Domestik PT. Lion Air”, 2012, p.1920

Jitendra Kumar Mishra, "Constituent Dimensions Of Customer Satisfaction: A Study Of Nationalised And Private Banks", Prestige Institute of Management\&Research India, 2007, p. 45-46

Juliet Namusaka, The influence of airline service quality on passenger satisfaction and loyalty :The case of Uganda airline industry, The TQM Journal; Vol. 25, No. $5 ; 2013$, p. 522

Kontan.com, "Hore, tarif bus dan taksi di Jakarta turun", http://regional.kontan.co.id/news/hore-tarif-bus-dan-taksi-di-jakarta-turun (Diakses 13 Juni 2016)

Kotler \& Keller, Marketing Management (United States : Pearson Education, Inc., 2016)

Kotler \& Armstrong, Principles of Marketing, 15th ed., (USA: Pearson Education Inc., 2014)

Lupiyoadi dan Hamdani, Manajemen Pemasaran Jasa, Edisi Kedua. Jakarta : Penerbit Salemba Empat, 2006, p. 127 
Mahanani, “Analisis Pengaruh Kualitas Pelayanan Terhadap Kepuasan Pelanggan Dalam Pembayaran Rekening Listrik ( Studi Pada Unit Pelayanan Pelanggan Semarang Barat )", Universitas Diponegoro, 2010, p. 46

Malhotra, Marketing Reasearch An Applied Orientation. 6th ed., (USA: Perason Education Inc., 2010) p.139

Marcelitha T. Montolalu, "The Impact Of Service Quality And Price To Customer Satisfaction And Customer Loyalty In Swiss-Belhotel Maleosan Manado” Jurnal EMBA, Vol.1 No.4 Desember 2013, p.1942

Pratiwi, "Analisis Pengaruh Harapan Pelanggan, Kualitas Produk, Kepuasan Pelanggan Terhadap Loyalitas Pelanggan Internet Flash Unlimited Di Semarang", Universitas Diponegoro, 2010, p. 39

Tariq M. Khizindar, et. al, An Empirical Study Of Factors Affecting Customer Loyalty Of Telecommunication Industry In The Kingdom Of Saudi Arabia, British Journal of Marketing Studies, 2015, p. 101

Reni Heviandri Riandarini, Ujang Sumarwan, Lilik Noor Yuliati, dan Kirbrandoko, "Comparison of Power Influence Factors Shaping Loyalty Indonesian Domestic Airlines", European Journal of Business and Management, Vol.7, No.11, 2015, p.122

Sanusi, Metodologi Penelitian Bisnis, (Jakarta: Salemba Empat, 2011), p.175

Schiffman \& Wisenblit. Consumer Behavior (New Jersey : Pearson Education, Inc, 2015), p. 16

Setiawati dan Sugiharto, "Analisis Tingkat Kepentingan Dan Kinerja Layanan Automatic Teller Machine (Atm) Bank Mandiri", Universitas Gunadarma, 2011, p. 2

Top Brand Award, http://www.topbrand-award.com/faq (Diakses tanggal 13 Juni 2016)

Sugihartono, "Analisis Pengaruh Citra, Kualitas Layanan Dan Kepuasan Terhadap Loyalitas Pelanggan (Studi Kasus Pada Pt. Pupuk Kalimantan Timur, Sales Representative Kabupaten Grobogan)”, Universitas Diponegoro, 2009, p. 17

Sugiyono, Statistika Untuk Penelitian, (Bandung: Alfabeta, 2013), p. 41

Suwandi, Andi Sularso, dan Imam Suroso, "Pengaruh Kualitas Layanan, Harga dan Citra Merek Terhadap Kepuasan Dan Loyalitas Pelanggan Pos Ekspres di Kantor Pos Bondowoso dan Situbondo", JEAM Vol. XIV April 2015, p.69-70

Tse \& Wilton, "The impact of corporate image and reputation on service quality, customer satisfaction and customer loyalty: testing the mediating role. Case analysis in an international service company", The Business and Management Review; Vol. 3, No. 2; 2013, p. 181

Usman Yousaf, et. al, Studying Customer Loyalty at Daewoo Express BusService Pakistan, Scientific Journal of Logistics, 2013, p. 147 
Jurnal Riset Manajemen Sains Indonesia (JRMSI) | Vol 6, No. 2, 2015

Vadjanasaregagul, "The Relationship Of Service Quality, Consum Er Decision Factors And Brand Equity", Nova Southeastern University, 2007, p. 24

Vickih Riady, "Analisis Pengaruh Kualitas Pelayanan, Harga Terhadap Loyalitas Pelanggan Studi Kasus pada PT Merpati Nusantara Airlines Semarang", Program Sarjana Fakultas Ekonomi dan Bisnis, Udinus, 2013, p.2

Walker \& Mullins, Marketing Strategy (New York : McGraw Hill, 2014), p. 259

Wirtz \& Lovelock, Services Marketing : People, Techonology, Strategy. Seventh Edition (United States : Pearson Education, Inc ., 2011), p. 154

Yunus, Bojei, et. all, "Service Quality towards Customer Loyalty in Malaysia's Domestic Low Cost Airline Service”, International Journal of e-Education, e-Business, eManagement and e-Learning, Vol. 3, No. 4, August 2013, p. 334 